\title{
A Drosophila genetic screen yields allelic series of core microRNA biogenesis factors and reveals post-developmental roles for microRNAs
}

\author{
PETER SMIBERT, ${ }^{1}$ FERNANDO BEJARANO, ${ }^{1}$ DONG WANG ${ }^{2}$ DANIEL L. GARAULET, ${ }^{1,3}$ JR-SHIUAN YANG, \\ RAQUEL MARTIN, ${ }^{1,3}$ DIANE BORTOLAMIOL-BECET, ${ }^{1}$ NICOLAS ROBINE, ${ }^{1}$ P. ROBIN HIESINGER, ${ }^{2}$ \\ and ERIC C. LAI ${ }^{1,4}$ \\ ${ }^{1}$ Department of Developmental Biology, Sloan-Kettering Institute, New York, New York 10065, USA \\ ${ }^{2}$ Department of Physiology and Green Center for Systems Biology, University of Texas Southwestern Medical Center, Dallas, Texas 75390, USA
}

\begin{abstract}
Canonical animal microRNAs (miRNAs) are 22 -nt regulatory RNAs generated by stepwise cleavage of primary hairpin transcripts by the Drosha and Dicer RNase III enzymes. We performed a genetic screen using an miRNA-repressed reporter in the Drosophila eye and recovered the first reported alleles of fly drosha, an allelic series of its dsRBD partner pasha, and novel alleles of dicer-1. Analysis of drosha mutants provided direct confirmation that mirtrons are independent of this nuclease, as inferred earlier from pasha knockouts. We further used these mutants to demonstrate in vivo cross-regulation of Drosha and Pasha in the intact animal, confirming remarkable conservation of a homeostatic mechanism that aligns their respective levels. Although the loss of core miRNA pathway components is universally lethal in animals, we unexpectedly recovered hypomorphic alleles that gave adult escapers with overtly normal development. However, the mutant photoreceptor neurons exhibited reduced synaptic transmission, without accompanying defects in neuronal development or maintenance. These findings indicate that synaptic function is especially sensitive to optimal miRNA pathway function. These allelic series of miRNA pathway mutants should find broad usage in studies of miRNA biogenesis and biology in the Drosophila system.
\end{abstract}

Keywords: microRNA; Drosha; Pasha; Microprocessor; synapse; Dicer

\section{INTRODUCTION}

microRNAs (miRNAs) are an abundant class of $\sim 22$-nt regulatory RNAs derived from endogenous inverted repeat transcripts, which collectively play substantial roles during development and homeostasis (Flynt and Lai 2008). Biogenesis of canonical animal miRNAs follows a conserved strategy involving stepwise cleavage by the Drosha and Dicer RNase III enzymes (Kim et al. 2009). In the Drosophila pathway, hairpins within primary miRNA (pri-miRNA) transcripts are recognized in the nucleus by the dsRNA binding domain (dsRBD) protein Pasha, which positions its partner Drosha to cleave $\sim 10$ bp into the stem (Han et al. 2006). The Drosha-Pasha complex is often referred to as the "Microprocessor," whose activity yields $~ 55-70$-nt pre-

${ }^{3}$ Present address: Centro de Biología Molecular Severo Ochoa (C.S.I.C.U.A.M.), Universidad Autónoma de Madrid, Nicolás Cabrera 1, Cantoblanco, 28049 Madrid, Spain.

${ }^{4}$ Corresponding author.

E-mail laie@mskcc.org.

Article published online ahead of print. Article and publication date are at http://www.rnajournal.org/cgi/doi/10.1261/rna.2983511.
miRNA hairpins (Denli et al. 2004; Gregory et al. 2004; Han et al. 2004). These are exported to the cytoplasm by Exportin5/Ran-GTP (Yi et al. 2003; Bohnsack et al. 2004; Lund et al. 2004) and cleaved again by Dicer-1 in complex with its dsRBD partner Loqs (Forstemann et al. 2005; Saito et al. 2005). One strand of each resulting duplex is preferentially loaded into the miRNA effector Argonautel (AGO1) (Forstemann et al. 2007; Tomari et al. 2007; Okamura et al. 2009), which partners with GW182 (Gawky) to repress target transcripts (Liu et al. 2005; Rehwinkel et al. 2005; Eulalio et al. 2008). As in other animals, functional Drosophila miRNA targets generally exhibit limited complementarity and frequently pair only to positions $2-8$ of the miRNA (Lai 2002; Ruby et al. 2007b), also known as the "seed" region (Bartel 2009). Productive regulatory interactions usually lead to target deadenylation and degradation, although translational inhibition and/or target relocalization also contribute to miRNAmediated silencing (Lai and Posakony 1997; Lai et al. 1998; Behm-Ansmant et al. 2006; Zdanowicz et al. 2009).

In addition to the canonical Drosha-Dicer pathway, several alternate pathways for miRNA biogenesis have been 
documented (Yang and Lai 2011). For example, mirtrons are short hairpin introns that are spliced and debranched to generate pre-miRNA hairpins, thereby bypassing the need for Drosha cleavage (Okamura et al. 2007; Ruby et al. 2007a). Variant mirtrons with $5^{\prime}$ or $3^{\prime}$ tails rely on splicing to generate one hairpin end but require other exonucleases to trim their tails to permit nuclear export and dicing (Babiarz et al. 2008; Flynt et al. 2010). Recently, vertebrate mir-451 was recognized to be Drosha-dependent but Dicerindependent, and instead matures via the catalytic activity of Ago2 (Cheloufi et al. 2010; Cifuentes et al. 2010; Yang et al. 2010). Nevertheless, the majority of miRNAs proceed through the canonical biogenesis pathway.

Most studies of miRNA biogenesis have relied on biochemical approaches and usage of RNA interference to reduce the activity of candidate factors, even in traditionally genetic systems such as Drosophila and Caenorhabditis elegans (Eulalio et al. 2007; Parry et al. 2007; Zhou et al. 2008). Consequently, there are few mutant alleles available for many key miRNA pathway genes. For example, in flies, there are only two alleles of dicer-1 (Lee et al. 2004; Berdnik et al. 2008), two alleles of pasha (Berdnik et al. 2008; Martin et al. 2009), and no mutant alleles described for drosha. The paucity of mutants limits the flexibility of genetic analysis for miRNA pathway function, especially in ways that would otherwise be facilitated by the availability of allelic series. For example, an extensive collection of dicer-2 alleles includes mutants that permit genetic separation of the role of this enzyme for siRNA genesis from its role in siRNA loading into AGO2 complex (Lee et al. 2004; Tomari et al. 2004; Lim et al. 2008).

Forward genetic screening offers a strategy to obtain mutants in an unbiased fashion and has the potential to identify new pathway components and accessory factors. In the present study, we describe a Drosophila genetic screen designed to identify mutants that affect the biogenesis or activity of canonical miRNAs. The efficacy of this screen was demonstrated by recovery of the first reported alleles of Drosophila drosha, the first point mutations of pasha, and several novel alleles of dicer-1. We use these alleles to demonstrate mutual cross-regulation of Drosha and Pasha levels, previously characterized only in cultured cells (Han et al. 2009; Kadener et al. 2009; Triboulet et al. 2009), for the first time in the intact animal. Finally, the availability of allelic series of these genes allowed us to access post-developmental roles of the miRNA pathway. In particular, we find that mild reduction of global miRNA levels leads to a synaptic transmission defect without overtly affecting development or neuronal maintenance.

\section{RESULTS}

\section{Development of a simple in vivo visual reporter for miRNA pathway activity}

To facilitate large-scale genetic identification of loci required for miRNA biogenesis or function, we designed a system to assay miRNA activity via simple visual inspection of eye pigmentation. A similar strategy was previously used successfully to identify genes involved in RNAi in Drosophila (Lee et al. 2004; Kim et al. 2007; Lim et al. 2008; Lee et al. 2009; Marques et al. 2010). To begin, we reprogrammed the mir-6-1 backbone (Chen et al. 2007) to generate an miRNA that targets a single location in the endogenous $3^{\prime}$ UTR of the white gene (w-miR) (Fig. 1A). To encourage miRNA-like biogenesis and target regulation (Forstemann et al. 2007; Czech et al. 2009; Okamura et al. 2009; Ghildiyal et al. 2010), we designed $w$-mir to have a central bulge in its pre-miRNA hairpin and mismatches at positions 10-12 relative to the target site (Fig. 1A). This miRNA was placed downstream from DsRed under control of GUS regulatory sequences (Brodsky et al. 2000); this hybrid element combines the GMR enhancer for specific expression in the developing eye and UAS sites for optional Gal4-mediated control. GUSDsRed-w-miR was carried in a P-element transformation vector containing a standard mini-white construct bearing the endogenous white 3' UTR.

To assay the regulatory activity of $\mathrm{w}-\mathrm{miR}$, we first performed sensor assays in S2 cells. Cotransfection of GUS-DsRed-w-mir and ub-Gal4 specifically repressed a Renilla luciferase reporter bearing the white 3' UTR, compared with controls (Fig. 1B). We next performed more physiological tests using third instar wing imaginal discs. We prepared a tub-GFP-white $3^{\prime}$ UTR transgene, which is expressed ubiquitously in the animal. When introduced into a background carrying GUS-DsRed-w-mir and ptc-Gal4, thus activating DsRed and $\mathrm{w}$-miR along the anterior-posterior compartment boundary, we correspondingly observed cellautonomous repression of the GFP-white 3' UTR sensor (Fig. 1C). Therefore, w-miR was able to silence transcripts bearing a single bulged site in the white $3^{\prime}$ UTR in vivo.

Finally, we assayed the capacity of $\mathrm{w}$-miR to suppress pigmentation. When placed in a background that is mutant for the endogenous white locus, GUS-DsRed-w-mir (hereafter abbreviated as $w$-mir) is autotargeting in the eye, since it generates both the white gene product from the miniwhite transformation marker in the vector backbone and an miRNA that silences this transcript. In principle, if such suppression were sufficiently robust, we may not have been able to score insertions based on standard rescue of eye pigment; we therefore included a DsRed selection marker. It turns out that multiple independent $w$-mir insertions were easily isolated, and these bore a range of eye colors as is typical for random $P$ integration. On the whole, these independent transgenes had mild levels of pigment (Fig. 1F, cf. wild-type in Fig. $1 \mathrm{E}$ and the white-null mutant in Fig. 1D).

To test if $\mathrm{w}$-miR was indeed responsible for this apparent decrease in eye pigment, we generated eye clones for a null mutation of $d c r-1$ (Lee et al. 2004) in the background of $\mathrm{w}$-miR. The resulting eyes appeared mosaic and had patches of tissue that were small and rough, as is characteristic of $d c r-1$ clonal tissue. Importantly, these mutant regions 

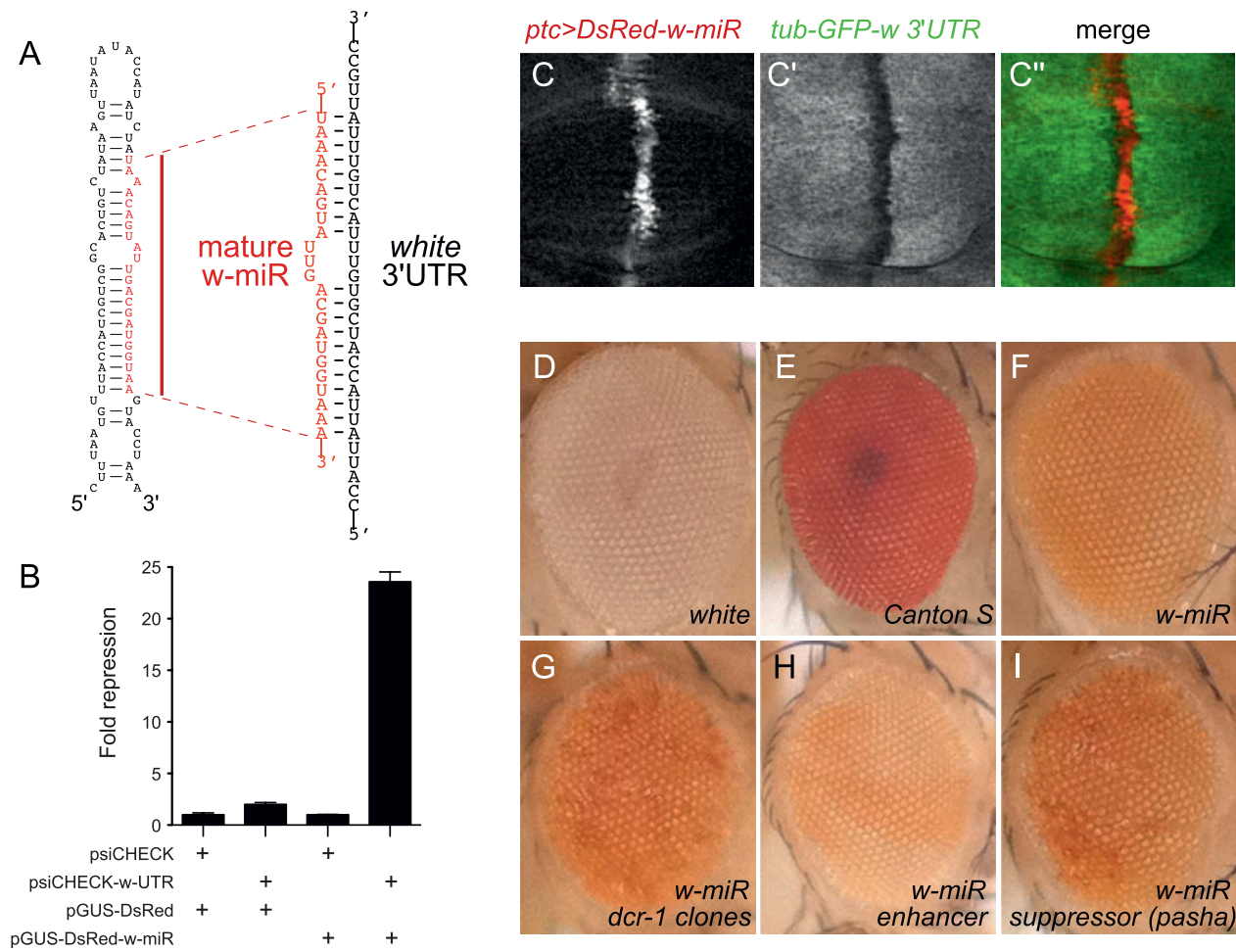

FIGURE 1. A synthetic miRNA directed against white is functional in vivo and a useful screening tool for miRNA biogenesis factors. ( $A$ ) Predicted secondary structure of $\mathrm{w}-\mathrm{miR}$ and its predicted interaction with the target sequence in the white $3^{\prime}$ UTR. The predicted mature strand is indicated in red. (B) S2 cells were transfected with the indicated plasmids, together with ub-gal4. Values represent fold repression of luciferase activity relative to empty psiCHECK vector. $(C)$ Wing disc sensor assay. w-miR expression driven by ptc-gal4 $(C)$ results in repression of tubGFP-w-3'UTR sensor $\left(C^{\prime}\right.$ and merge, $\left.C^{\prime \prime}\right)$. $(D)$ A white eye. $(E)$ A wild-type (Canton $S$ ) eye. (F) Eye of an animal with pGUS-DsRed-w-miR transgene. $(G)$ Clones of $d c r-1[Q 1147 X]$ in the background of GMR-w-miR result in a mosaic eye with darker patches. $(H)$ Example of presumed enhancer of miR-mediated silencing from our screen (gene unknown). (I) Example of suppressor of miR-mediated silencing from our screen (pasha[23D2], which is a newly isolated null mutant of pasha that results in the premature truncation of Pasha at R308).

exhibited darker red pigmentation than surrounding tissue, indicating that $d c r-1$, and by inference the miRNA pathway, was required for w-miR-mediated suppression of eye pigmentation (Fig. 1G). We concluded that $\mathrm{w}-\mathrm{miR}$ is a suitable reagent with which to carry out forward genetic screening for loci required for the miRNA pathway.

\section{Genetic screening using w-miR recovers novel Microprocessor mutations}

We used the suppression of eye pigment by $\mathrm{w}-\mathrm{miR}$ as the basis of $\mathrm{F}_{1}$ genetic screens of the right arms of chromosome 2 and 3; screening of other chromosome arms is ongoing. We scored for eyes exhibiting mosaicism of eye color, then backcrossed and retested these for germline transmission of mutations and reproducibility of pigment modification. In principle, clonal changes in eye color can result in lighter patches (in which case, the mutation potentially enhances miRNA activity) or darker pigment (in which case, the mutation potentially suppresses miRNA activity). Examples of enhancers and suppressors of $\mathrm{w}$-miR are shown in Figure $1 \mathrm{H}$ and $1 \mathrm{I}$, respectively. Of course, it is also possible that clonal changes in eye color were due to mutations in the pigment biosynthetic pathway. Therefore, we performed a secondary test for the dependence of pigment modification on w-miR. Instead of using the eyflp transgene to generate clones, we used a chromosome with ey-gal4 and UAS-FLP, both of which are carried on transgenes that use white ${ }^{+}$as a selectable marker (Stowers and Schwarz 1999). Any mutant alleles that gave eye color mosaicism in this background were discarded because their effect on pigmentation is not w-miR-dependent. A full description of mutants isolated from these screens will be reported elsewhere (P Smibert and EC Lai, in prep.).

Two suppressor mutations recovered from chromosome 3R, Su6B3 and Su14D4, failed to complement each other and also failed to complement a previously described pasha deletion allele, pasha[KO] (Martin et al. 2009). We isolated genomic DNA from larvae trans-heterozygous for these mutations against pasha[KO], and amplified and sequenced the mutant pasha locus. Both alleles had missense mutations in the coding exons of pasha (Fig. 2A,D,E). Three suppressor mutations on chromosome 2R-Su6M1, Su15N1, and Su21K11-also exhibited eye mosaicism with patches of more pigment (Fig. $2 \mathrm{~L}-\mathrm{N}$ ). All three failed to complement $D f(2 R)$ exel6055, which uncovers 33 genes (http:// flybase.org/), including drosha. Sequencing of DNA from 

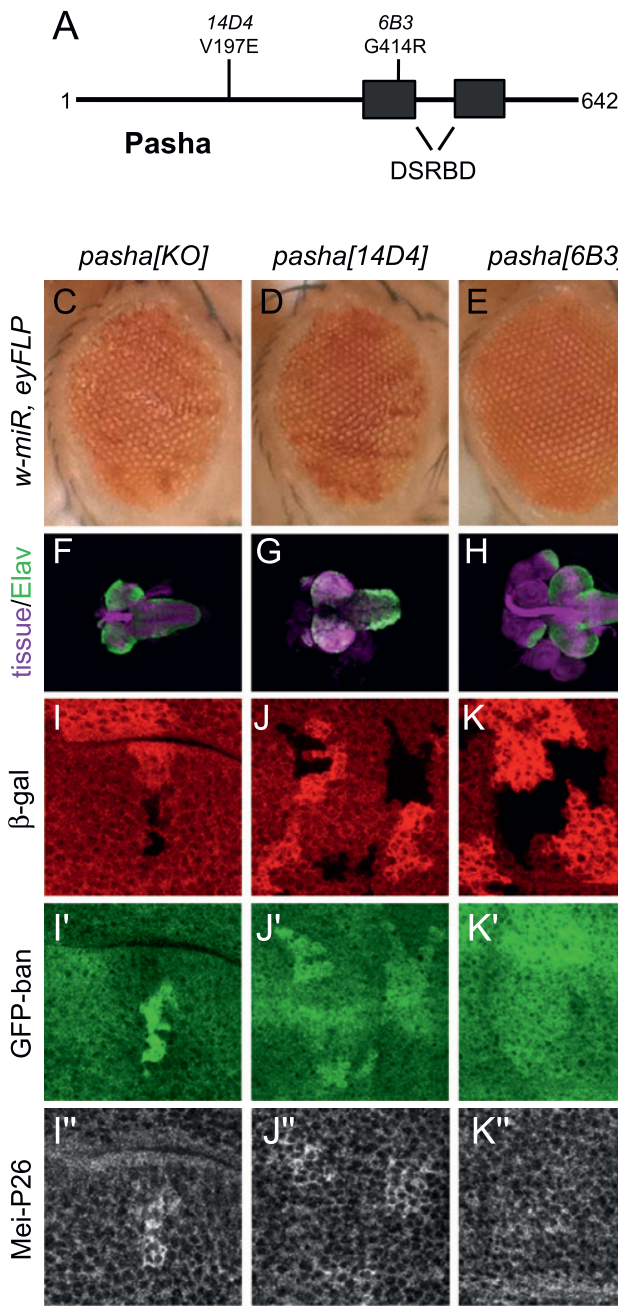
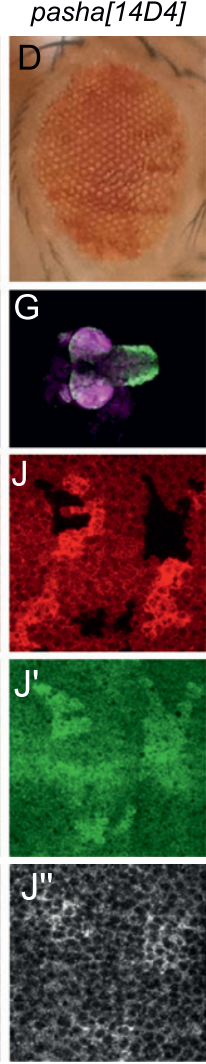

pasha[6B3]
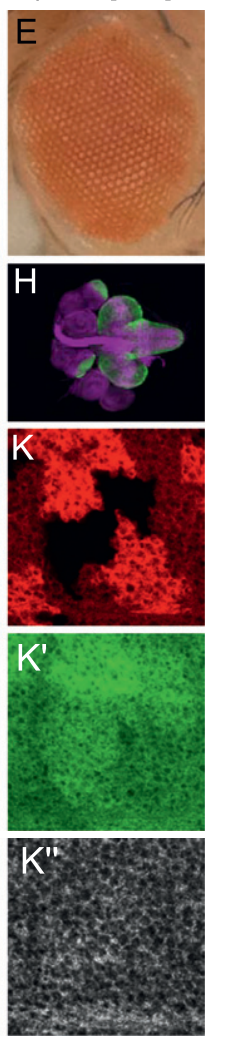
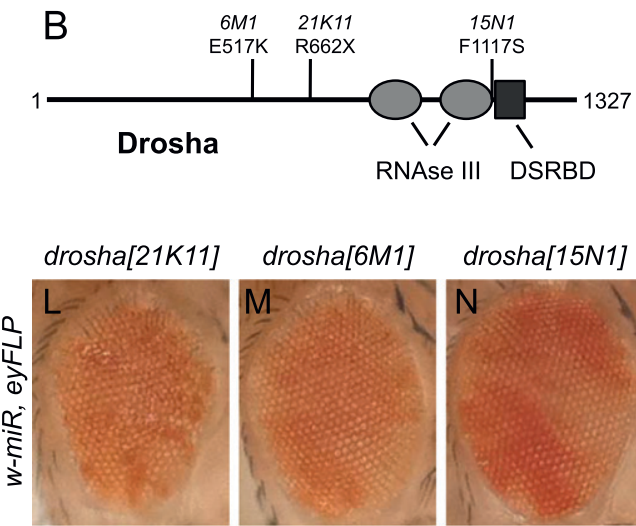

drosha[15N1]
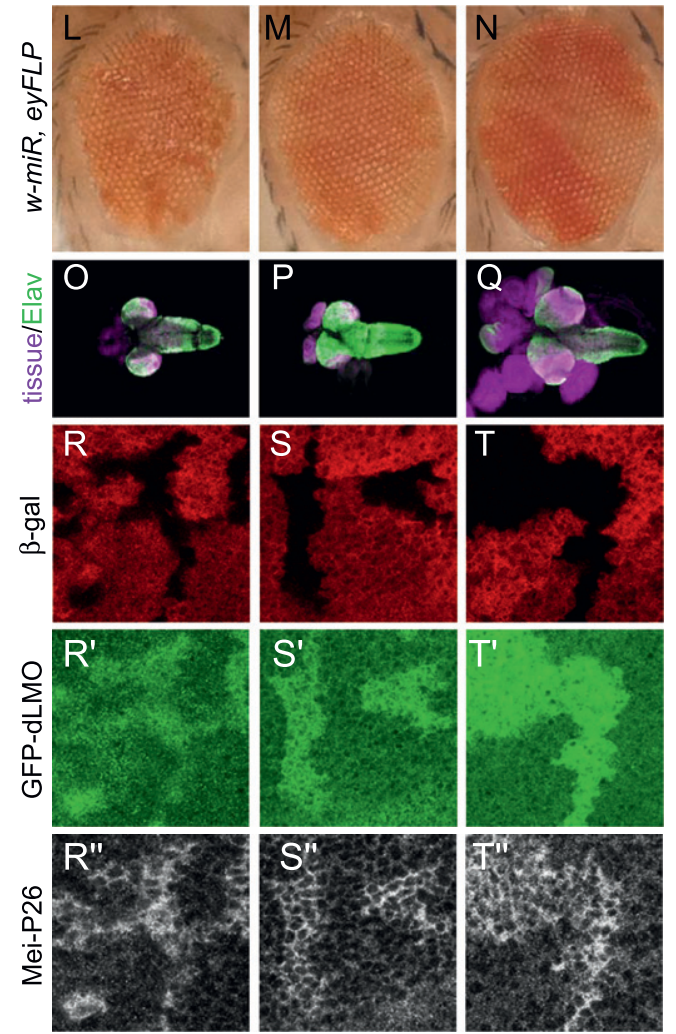

FIGURE 2. Identification and characterization of novel Microprocessor alleles. (A) Molecular lesions of pasha alleles. pasha[KO] is a complete locus deletion that has been described previously (Martin et al. 2009). (B) Molecular lesions of drosha alleles. ( $C-K$ ) Phenotypic characterization of pasha alleles: $(C-E)$ Adult eyes with clones of the indicated genotype in the background of GMR-w-miR. Note that the pasha[KO] allele itself has a $w[+]$ transgene and is included only for comparison of morphology, not pigmentation. $(F-H)$ Third instar disc clusters of indicated alleles in trans with pasha [KO] stained with Elav (green) and a tissue marker (Phalloidin, [KO] and [6B3]; or Hoechst, 33352-[14D4], purple). (I-K) Mitotic clones of indicated alleles marked by the absence of $\beta$-gal (red) and stained for GFP-ban sensor (green, $\left.I^{\prime}-K^{\prime}\right)$ and Mei-P26 (grayscale, $\left.I^{\prime \prime}-K^{\prime \prime}\right)$. ( $L-T$ ) Phenotypic characterization of drosha alleles: $(L, M)$ Adult eyes with clones of the indicated genotype in the background of GMR-w-miR. (O-Q) Third instar disc clusters of indicated alleles in trans with $D f(2 R)$ exel6055 stained with Elav (green) and a Hoechst 33352 (purple). (R-T) Mitotic clones of indicated alleles marked by the absence of $\beta$-gal (red) and stained for GFP-ban sensor (green, $R^{\prime}-T^{\prime}$ ) and Mei-P26 (grayscale, $R^{\prime \prime}-T^{\prime \prime}$ ).

larvae trans-heterozygous for $D f(2 R)$ exel6055 and each mutation revealed that all had nonsynonymous mutations in drosha-coding exons (Fig. 2B). One of these alleles, Su21K11, carried an R662X mutation that results in premature termination of the protein before the RNase III domains and is therefore expected to be a null mutant. This mutant behaves genetically as a null, as homozygotes are indistinguishable from animals trans-heterozygous for this allele and $D f(2 R)$ exel6055 (data not shown). To our knowledge, these represent the first reported mutant alleles of drosha in Drosophila.

These Microprocessor mutants were all recovered on the basis of clonal derepression of white ${ }^{+}$function in the eye, but different alleles had distinct effects on eye morphology. Eyes bearing null clones for either pasha or drosha were smaller and rough, with disorganized or absent ommatidia (Fig. 2C,L). Eyes bearing clones of pasha[14D4] or drosha[6M1] were slightly less phenotypically severe than their respective null mutants (Fig. 2D,M). In contrast, clones for pasha[6B3] or drosha[15N1] appeared morphologically normal, with no obvious defects in ommatidial size or organization (Fig. $2 \mathrm{E}, \mathrm{N})$. Additionally, clones of these mutants occupied $\sim 50 \%$ of the eye, compared with the stronger mutants whose clones occupied much less. This indicated a growth disadvantage for strong pasha and drosha alleles that was absent from the corresponding weak alleles.

To assess the overall developmental consequence of flies mutant for our novel alleles, we examined third instar brain 
and imaginal disc clusters. To rule out potential contributions from second site mutations, as well as to provide direct comparison of allelic strengths, we placed each pasha or drosha allele in trans to the pasha[KO] or $D f(2 R)$ exel6055 deletions, respectively. For simplicity, we refer to these trans-heterozygous allelic combinations by the allele of interest. Homozygous pasha[KO] animals were used because these animals are rescued to viability with a genomic rescue transgene (Martin et al. 2009).

As described previously (Martin et al. 2009), pasha[KO] animals form small third instar larvae that are almost completely devoid of imaginal discs (Fig. 2F). These animals die as larvae or poorly formed early pupae. Some larvae develop rudimentary eye discs, but most animals lack any obvious imaginal discs. pasha[14D4] mutants have rudimentary eye discs that stain for the neural marker Elav (Fig. $2 \mathrm{G})$, and these animals die as early pupae. In contrast, pasha [6B3] animals have a virtually wild-type complement of imaginal discs surrounding a normally sized brain and go on to die as pharate adults (Fig. $2 \mathrm{H}$ ). Similar to pasha-null animals, drosha[21K11] animals die as third instar larvae or poorly formed early pupae. At the third larval instar, these animals are almost completely lacking imaginal disc structures (Fig. 2O). drosha[6M1] animals exhibit an intermediate phenotype with respect to imaginal tissues at the third larval instar, with rudimentary Elav positive eye discs, but no other imaginal tissues (Fig. 2P). In contrast, drosha[15N1] animals have a full complement of imaginal discs and look morphologically indistinguishable from wild type (Fig. 2Q). While trans-heterozygotes of drosha[15N1] over the deletion die as pharate adults, drosha[15N1] homozygotes occasionally survive to adulthood.

\section{Differential defects in miRNA biogenesis and function in Microprocessor mutants}

It was unexpected that screening for failure to repress a miRNA-sensitive reporter could yield pasha and drosha alleles that could survive to adulthood, as the miRNA pathway is universally essential for viability in all animals. We therefore conducted a detailed series of functional assays of miRNA biogenesis and function on our allelic series of pasha and drosha mutants. We first generated mitotic clones in the wing imaginal disc and assayed for the levels of previously described sensors of miRNA activity. We used tub-GFP-bantam and tub-GFP-dLMO, which are ubiquitously expressed GFP transgenes driven by the $\beta$-tubulin promoter followed by two copies of a sequence complementary to the bantam miRNA, or the $3^{\prime}$ UTR of the miRNA-regulated gene dLMO (Brennecke et al. 2003; Bejarano et al. 2010). Additionally, we stained for endogenous Mei-P26 protein, a miRNA target that is derepressed in $d c r-1$ and ago1 mutant clones (Herranz et al. 2010). In all alleles examined, homozygosity for the Microprocessor mutations resulted in derepression of both the GFP sensors and Mei-P26 (Fig. 2I-K,R-T). In the case of pasha mutations, the level of derepression of both GFP-ban and MeiP26 correlated with allele strength with strong derepression for the null mutant and only very mild derepression in the weak pasha[6B3] clones (Fig. 2I-K). However, despite the difference in phenotypic severity of the drosha alleles examined at the level of morphology, no obvious differences in the level of derepression of either GFP-dLMO or Mei-P26 were observed (Fig. 2R-T). In other words, these weak drosha alleles nevertheless exhibited strong derepression of artificial and even endogenous miRNA targets.

The roles of Drosha in miRNA biogenesis, rRNA maturation, and mRNA cleavage have been extensively studied in vitro using biochemistry and knockdowns in cultured cells, but in vivo studies are comparably limited. We took the opportunity to test the requirements for Drosha in RNA metabolism using these first-available Drosophila drosha mutants. The best characterized role for Drosha is to cleave pre-miRNAs from primary miRNA transcripts (Lee et al. 2003; Denli et al. 2004; Gregory et al. 2004; Han et al. 2004; Landthaler et al. 2004). A subset of miRNAs is produced from Drosha-independent substrates, including mirtrons, which are short hairpin introns that use splicing to generate the pre-miRNA (Okamura et al. 2007; Ruby et al. 2007a). Our studies of a pasha knockout verified that this Drosha cofactor was required for in vivo maturation and function of canonical miRNAs but not mirtrons (Martin et al. 2009). Here, we demonstrate the direct involvement of the Drosha nuclease for canonical miRNA biogenesis in the animal. qRT-PCR assays of 5-6d-old third instar larvae revealed strong accumulation of primary miRNA transcripts in drosha[21K11] animals, comparable to pasha[KO] animals isolated in parallel (Fig. $3 \mathrm{~A})$. Northern analysis of the whole panel of Microprocessor mutants showed that levels of mature miR-14, miR-2a, and miR-9a were decreased in all cases, whereas mirtronderived miR-1003 was unaffected in any of the mutants (Fig. 3B).

Notably, for both pasha and drosha mutants, the level of reduction in mature miRNAs correlated with the strength of developmental and viability defects observed. The strongest loss of mature miRNA species was observed for the null mutations, pasha[KO] and drosha[21K11], followed by the intermediate strength mutations, pasha[14D4] and drosha[6M1]. The weak hypomorphic mutations, pasha[6B3] and drosha[15N1], had only modest reductions in mature miRNA levels, consistent with the modest phenotypes associated with their homozygosity (Figs. 2C-H,L-Q, $3 \mathrm{~B})$. Given this correlation, it was surprising that we observed strong derepression of multiple miRNA sensors and even of the endogenous miRNA target Mei-P26 in mutant clones of drosha[15N1], a weak allele that exhibits only subtle effects on absolute mature miRNA levels. We hypothesize that certain readouts and/or targets of miRNAmediated repression are more sensitive than others, a ge- 

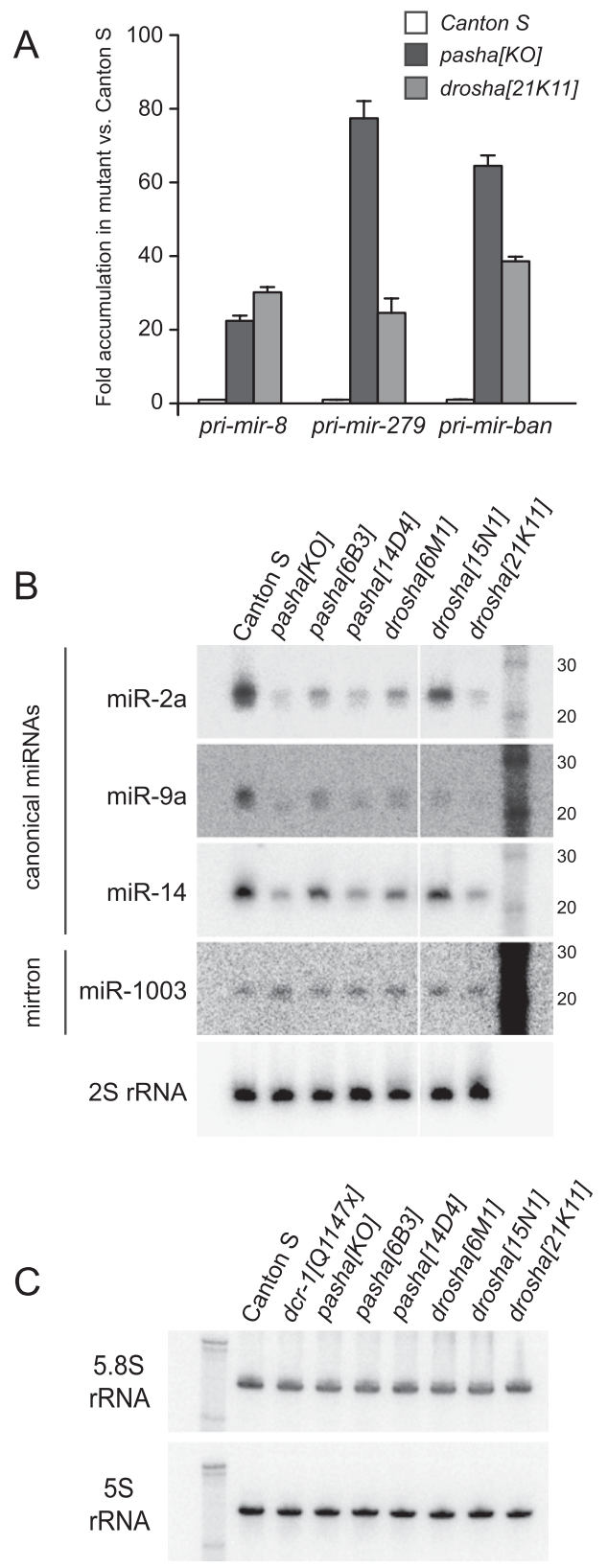

FIGURE 3. Effects of Microprocessor mutants on small RNA maturation. (A) Accumulation of pri-miRNA transcripts in null Microprocessor mutants. Total RNA was extracted from Canton S, homozygous pasha[KO], or trans-heterozygous drosha[21K11]/ $D f(2 R)$ exel6055 animals and assayed by qRT-PCR. The $y$-axis represents the fold up-regulation of the indicated miRNA relative to the Canton S sample and standard deviation. (B) Mature miRNA levels in Microprocessor mutants. Total RNA was extracted from third instar larvae of the indicated genotypes. For the pasha alleles, indicated alleles were in trans with pasha[KO]. For the drosha alleles, indicated alleles were in trans with $D f(2 R)$ exel6055. The small RNA blot was sequentially probed as indicated. $2 \mathrm{~S}$ rRNA was used as a loading and transferring control. $(C)$ Ribosomal RNA maturation is unaffected in Microprocessor mutants. RNA from the same samples was run simultaneously on two gels, transferred, and probed for $5 \mathrm{~S}$ and $5.8 \mathrm{~S}$ rRNA. netic situation that can be appreciated by availability of an allelic series. We revisit the biological implications of this below in this study.

Drosha was initially identified as an RNase III enzyme required for maturation of ribosomal RNAs. Antisense inhibition of Drosha resulted in accumulation of $12 S$ and $32 \mathrm{~S}$ rRNA species, interpreted as a partial block in rRNA processing (Wu et al. 2000). Subsequently, loss of the Microprocessor accessory factors, the DEAD-box helicases p68 and p72, was reported to decrease 5.8S rRNA maturation (Fukuda et al. 2007). We analyzed 5.8S rRNA levels across our panel of Microprocessor mutants at the third larval instar, which are presumably depleted of stores of maternal protein inherited 5-6 d earlier. However, we did not observe any obvious differences from control Canton $\mathrm{S}$ animals (Fig. 3C). The absence of rRNA biogenesis defects in drosha null flies parallels an analysis from Drosha knockout mouse thymocytes, which indicated no defects in rRNA levels (Chong et al. 2008).

\section{In vivo demonstration of cross-regulation of the Microprocessor}

In addition to its major role in nuclear miRNA biogenesis, Drosha also cleaves certain mRNA hairpins. Its most wellcharacterized mRNA target encodes DGCR8, the mammalian ortholog of Pasha (Han et al. 2009; Triboulet et al. 2009). Reciprocally, DGCR8/Pasha proteins are required for Drosha stability, thus fulfilling a post-transcriptional and post-translational homeostatic loop that tunes appropriate levels of these core Microprocessor components (Han et al. 2009). Studies in S2 cell culture showed that the capacity of Drosha to cleave and down-regulate pasha transcript is conserved in Drosophila (Han et al. 2009; Kadener et al. 2009).

We used our Microprocessor mutant alleles to perform strict genetic tests of the Microprocessor cross-regulatory loop in the animal. Mitotic clones of drosha[21K11] showed derepression of both an endogenous miRNA target and a sensor for miRNA activity (Fig. 2R) and a strong reduction of Drosha (Fig. 4A). Unfortunately, the available Drosha antibody (Denli et al. 2004) is not entirely specific in tissue staining but exhibits strongly decreased immunoreactivity in drosha-null clones. Mitotic clones of pasha $[\mathrm{KO}]$ also showed derepression of both an endogenous miRNA target and a sensor for miRNA activity (Fig. 2I). Furthermore, pasha[KO] clones exhibited strongly reduced Drosha staining equivalent to drosha mutant clones (Fig. 4B), indicating that Drosophila Pasha is required for Drosha stability in the animal.

Knockdown of drosha in S2 cells increases pasha transcript levels (Han et al. 2009), but the effect on Pasha protein was unknown. We generated mitotic clones of null mutants of pasha (Martin et al. 2009), dicer-1 (Lee et al. 2004), and drosha (this work), all of which derepress miRNA sensors and endogenous miRNA targets (Figs. 2, 4D-F), and assayed 


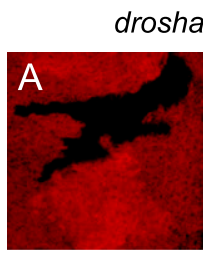

$\beta$-gal

C

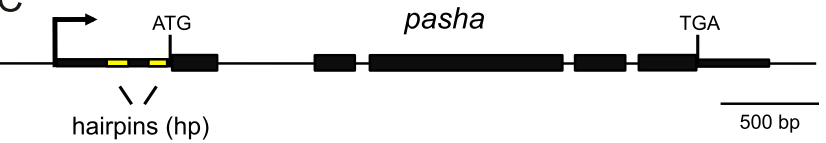

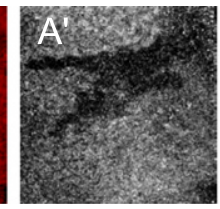

Drosha

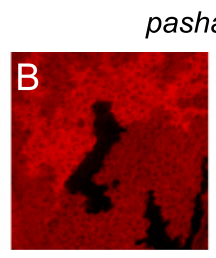

$\beta$-gal

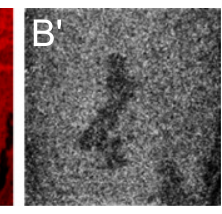

Drosha
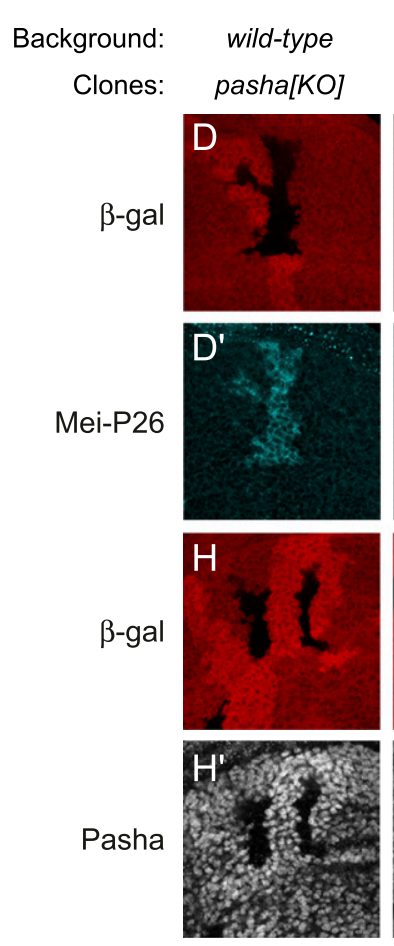
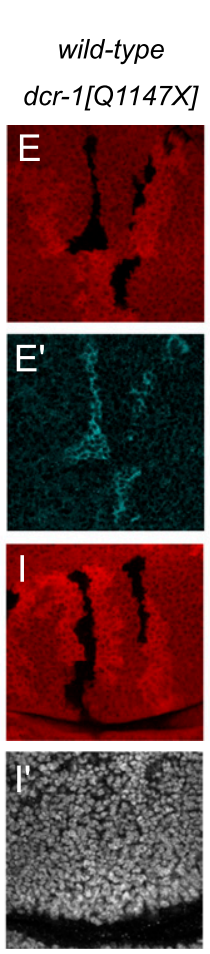

\section{wild-type}
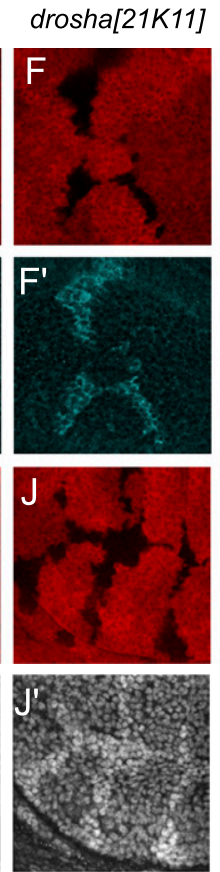

FIGURE 4. In vivo cross-regulation of Microprocessor components in Drosophila. In all cases, mutant clones are marked by the absence of $\beta$-gal (stained in red). (A) A clone for drosha[21K11] has strongly reduced Drosha staining $\left(A^{\prime}\right)$. (B) A pasha[KO] clone also has strongly reduced Drosha staining $\left(B^{\prime}\right)$. (C) Schematic representation of pasha locus demonstrating position of $5^{\prime}$-UTR hairpins. $(D-G)$ Clones of pasha[KO] $(D)$, dcr$1[Q 1147 X](E)$, and drosha[21K11], either in a wild-type background $(F)$ or in a background homozygous for pasha $[\mathrm{KO}]$ rescued by two copies of a pasha genomic rescue fragment lacking the two hairpins in the $5^{\prime}$ UTR $(G)$ exhibit derepression of Mei-P26 $\left(D^{\prime}-G^{\prime}\right)$, indicating loss of miRNA pathway activity. $(H-K)$ Clones of the same genotypes as $D-G$ have different effects on Pasha levels $\left(H^{\prime}-K^{\prime}\right) .(H)$ Clones of pasha[KO] have no detectable Pasha staining. (I) Pasha levels are unaffected in $d c r-1[Q 1147 X]$ clones. $(J)$ Pasha protein is elevated in clones of drosha[21K11]. (K) In a genetic background homozygous for the pasha[KO] allele but rescued with two copies of a pasha genomic rescue transgene lacking the two hairpins in the $5^{\prime}$ UTR, clones for drosha[21K11] do not have altered Pasha levels.

Pasha protein levels. As expected, clones homozygous for a null pasha mutant lack Pasha completely (Fig. 4H). Clonal loss of Dcr-1 had no discernible effect on Pasha levels (Fig. 4I), demonstrating that Pasha levels are not significantly affected by global reduction of miRNAs. However, loss of Drosha,

pasha[KO], $P$ [pasha $\Delta h$ p] drosha[21K11]
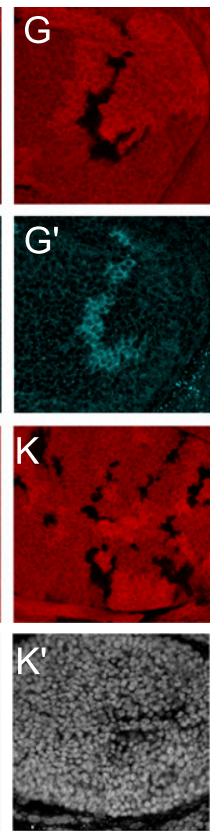

which also globally reduces miRNAs and miRNA pathway activity (Figs. 2R, 4F), resulted in a cell-autonomous increase in Pasha (Fig. 4J). Since Pasha protein was not up-regulated in $d c r-1$ clones, its upregulation in drosha clones is miRNAindependent and instead consistent with direct cleavage of pasha transcript by Drosha.

We performed a stringent test of this notion by introducing a mutated pasha genomic construct into the pasha deletion background, such that the only source of pasha was transgenically expressed under endogenous transcriptional control. We identified two pasha $5^{\prime}$-UTR hairpins that generated short RNA reads consistent with a low level of miRNA-like biogenesis (Supplemental Fig. 2) and deleted these from the construct. This transgene was inserted onto chromosome 3L and recombined with pasha $[\mathrm{KO}]$. We then introduced this recombinant third chromosome into the FRT42D drosha[21K11] background and generated negatively marked $h s-F L P$ clones. In this experiment, despite the loss of Drosha and the derepression of an endogenous miRNA target (Fig. 4G), the level of Pasha protein was unchanged (Fig. 4K). This confirms that despite the different primary sequences of the hairpins, the molecular logic and precise cross-regulation of Microprocessor components is conserved between Drosophila and mammals.

\section{Synaptic function is sensitive to global reduction of miRNA levels in photoreceptor neurons}

In Drosophila, as in other organisms, loss of core components of the miRNA pathway causes a plethora of developmental consequences (Lee et al. 2004; Hatfield et al. 2005; Jin and Xie 2007; Park et al. 2007; Martin et al. 2009). However, it is difficult even with conditional knockout techniques to bypass developmental effects. Our hypomorphic mutants of core miRNA pathway components provided an opportunity to assess the relative sensitivity of development, function, and maintenance on miRNA levels in a specialized cell type. In particular, the observation that the misregulation of certain miRNA targets did not strictly correlate with overall status of 
the miRNA pathway suggested that it might be possible to discern specific cellular settings that are especially sensitive to miRNA levels.

In addition to our weak drosha[15N1] and pasha[6B3] alleles, our screen isolated novel alleles of $d c r-1, d c r-1$ [18E6], and $d c r-1$ [19E2], which have missense mutations in the double-stranded RNA binding domain and the second RNase III domain, respectively (Fig. 5A). These hypomorphic mutations exhibited $\mathrm{w}$-miR derepression and adult eye clonal morphology reminiscent of our previously described pasha [6B3] and drosha[15N1] hypomorphic alleles (Figs. 2E,N, 5B-D). They yielded morphologically normal, pharate adult lethal animals with some escapers in trans with either a $d c r$-1-null mutation, $d c r-1[Q 1147 X]$, or a deficiency that removes the $d c r-1$ locus, $D f(3 R) E D 6906$ (Lee et al. 2004; Ryder et al. 2007). Together with the hypomorphic pasha [6B3] and drosha[15N1] alleles, we used these reagents to assess postdevelopmental roles for the miRNA pathway in the eye.

Since external morphology does not reliably report on possible defects of internal structures, we first performed
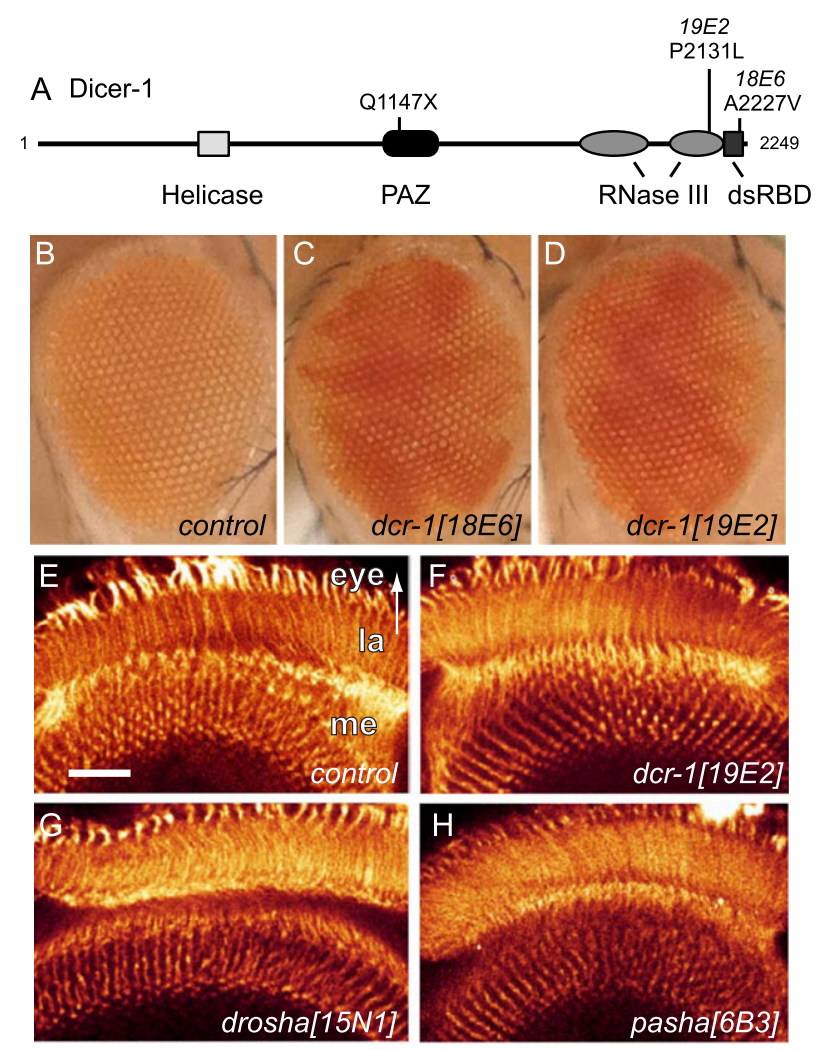

FIGURE 5. Hypomorphic miRNA pathway mutants exhibit normal eye development. (A) Schematic representation of Dcr-1 protein with positions of missense mutations dcr-1 [18E6] and dcr-1[19E2] and nonsense mutation dcr-1[Q1147X] (Lee et al. 2004) indicated. (B) Control $w$-miR eye. Eyes bearing clones of dcr-1[18E6] (C) or dcr1[19E2] $(D)$ in the background of $w$-miR exhibit derepression of the white reporter, seen as darker red pigmentation, but otherwise lack roughness that might indicate aberrant development. $(E-H)$ In comparison to wild type, hypomorphic mutants of $d c r-1, d r o s h a$, and pasha all exhibit normal patterns of photoreceptor projections to the central brain. additional analysis on animals bearing whole eye clones of hypomorphic miRNA biogenesis mutants. These tests indicated normal specification of photoreceptor and support cells. Moreover, the mutant photoreceptors retained normal targeting properties and established layer-specific terminals in the optic neuropils lamina and medulla that are indistinguishable from wild type (Fig. 5E-H). These findings demonstrated that development and wiring of the eye was not substantially affected by a mild reduction in miRNA biogenesis.

Photoreceptor neuron function and maintenance (or degeneration) is easily assessed through electroretinogram recordings (Williamson et al. 2010). Electroretinograms (ERGs) are extracellular recordings of the photoreceptor response to a light stimulus that exhibit two main features: The depolarization amplitude, which is reduced when phototransduction or cell health is defective or degrades over time, and the "on" transient, a post-synaptic response that is lost when synaptic transmission is blocked (Fig. 6A). Hence, ERGs provide a measure for both neuronal degeneration and function over time.

We performed ERGs on whole eye clones of our miRNA pathway hypomorphic mutants using the ey3.5FLP system, which selectively renders the pre-synaptic photoreceptor neurons mutant (Fig. 6B; Chotard et al. 2005; Mehta et al. 2005). Whole eye clones of pasha[6B3] showed no substantial difference in the amplitude of depolarization compared with control eyes, indicating that this mutation does not affect the photoreceptor response to stimulation. However, pasha[6B3] ERGs exhibited significantly decreased "on" transients. This defect is significantly rescued by including a single copy of a pasha genomic rescue construct in the pasha[6B3] background. We saw a stronger reduction of "on" transient amplitude in drosha [15N1] whole eye clones, which we could also rescue to near wild-type levels with a single copy of a drosha genomic rescue construct. In addition, our two independent hypomorphic $d c r-1$ alleles displayed significant reduction in "on" transient amplitude with no significant effect on depolarization (Fig. 6B). The synaptic transmission defects cannot be attributed to post-synaptic neurons because only the pre-synaptic photoreceptors were mutant in these experiments. Taken together, our findings reveal a specific loss of neurotransmission in hypomorphic alleles for drosha, pasha, and $d c r-1$ that all mildly reduce miRNA levels without affecting development. These data suggest that synaptic transmission is more sensitive to miRNA levels than development of photoreceptor neurons.

It was conceivable that a gradual loss of synaptic transmission precedes neuronal degeneration in the presence of reduced miRNA pathway activity. To test this notion, we compared the depolarization and "on" transients of drosha[15N1] and pasha[6B3] in 1-wk and 3-wk aged flies. As shown in Figure 6B,C, the recordings were virtually identical. We conclude that neither the healthy depolarization upon light stimulation nor the synaptic transmission 

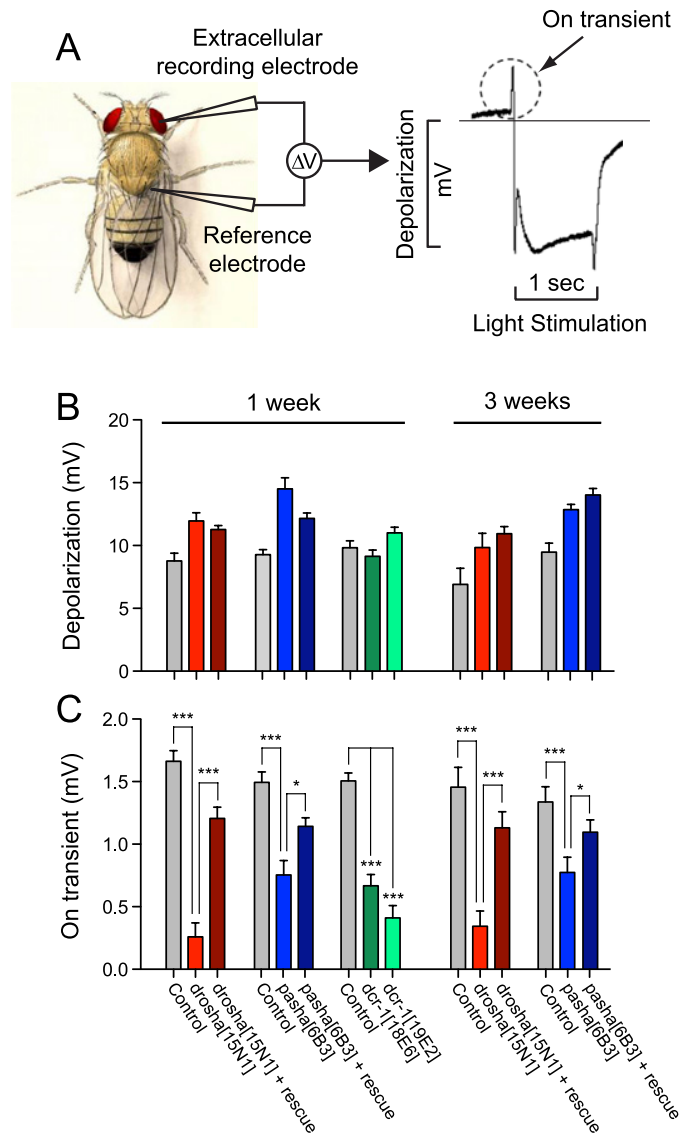

FIGURE 6. Hypomorphic alleles of miRNA pathway components have specific synaptic transmission defects. (A) Illustration of the ERG procedure and description of measurements. Electroretinograms (ERGs) were performed on animals with whole eye clones of the indicated mutant alleles (see also Materials and Methods). (B) Depolarization and $(C)$ "on" transient amplitude measurements of indicated genotypes. Whole eye clones of drosha[15N1] and pasha[6B3] result in significant loss of "on" transient amplitude that is rescued by a single copy of a genomic rescue transgene. Two independent alleles of $d c r-1$ also exhibited a significant loss of "on" transient amplitude. In all cases, depolarization of the photoreceptor cell bodies was not significantly different from controls. ERG analysis in 3-wk-old flies revealed no change in "on" transient amplitude or depolarization in any genotypes examined, demonstrating an absence of large-scale photoreceptor degradation or death. Values represent the mean depolarization or "on" transient amplitude of $>10$ flies per genotype \pm standard error of the mean. ${ }^{\star *} P<0.01,{ }^{\star} P<0.05$.

defect deteriorates over time. These findings suggest that the reduced neurotransmission in the Microprocessor hypomorphs is not secondary to neuronal maintenance defects and, reciprocally, that miRNA function is acutely required for synaptic function.

\section{DISCUSSION}

\section{An efficient in vivo genetic screen for miRNA pathway components}

In this study, we describe a forward genetic screen for factors involved in miRNA biogenesis or function and validate its utility by characterizing a series of core miRNA pathway mutants. We used these to investigate Microprocessor cross-regulation in vivo, as well as to study post-developmental roles of miRNAs in neural function. In particular, we provide the first loss-of-function analysis of Drosophila drosha. As expected, we observed a strong block in canonical miRNA biogenesis in the drosha-null mutant, which accumulated primary miRNA transcripts and was depleted of mature miRNAs, similar to pasha mutants (Martin et al. 2009). In addition, we found mirtron biogenesis to be unaffected by drosha mutation, providing direct evidence that these splicing-derived miRNAs are completely independent of the Drosha nuclease. Animals null for drosha and pasha are generally similar with respect to all phenotypes examined, supporting the obligate nature of these core protein partners within the Microprocessor complex.

Our screen generated allelic series for the key Microprocessor components drosha and pasha. These allowed us for the first time to assess the sensitivities of development versus function in cells with mildly reduced miRNA levels. Compared with full knockouts that give only null states, forward genetic screening can yield allelic series of varying phenotypic severity, which can uncover interesting aspects of pathway and gene function. We note that our hypomorphic drosha and pasha mutants have very different effects in different assays, as highlighted by the differences in derepression of both an endogenous miRNA target and a transgenic sensor for miRNA activity between our weak drosha and pasha alleles (Fig. 2). This is the case despite the fact that these mutants have similar effects on total mature miRNA levels as measured by Northern blot (Fig. 3B). The reason for this phenotypic discrepancy is not yet clear but suggests the possibilities that miRNAs are differentially sensitive to availability of the core biogenesis machinery or that specific biological processes are especially sensitive to optimal miRNA biogenesis. Indeed, we have provided electrophysiological evidence of the latter, and both of these hypotheses represent compelling future directions for analysis of these and other mutants that may emerge from genetic screening.

The theme of miRNA pathway autoregulation has emerged at multiple levels in animals (Forman et al. 2008; Han et al. 2009; Kadener et al. 2009; Triboulet et al. 2009; Martello et al. 2010; Bennasser et al. 2011) and in plants (Xie et al. 2003; Vaucheret et al. 2004; Rajagopalan et al. 2006; Vaucheret et al. 2006). Our in vivo demonstration of the reciprocal regulation of the core Microprocessor components reveals that this mechanism is conserved and occurs within the intact animal. The role of Pasha within the Microprocessor to position Drosha catalytic centers is clearly of crucial importance to miRNA biogenesis. Perhaps the instability of Drosha in the absence of Pasha is a biological safeguard to prevent inappropriate cleavage of transcripts by Drosha in the absence of Pasha. Likewise, the capacity of Drosha to cleave pasha transcripts may also limit Drosha 
levels by restricting the amount of Pasha for it to associate with.

Our studies to date focused on mutants of known miRNA pathway components. This has been a productive effort, as indicated by our first reported Drosophila alleles of drosha, the first allelic series of pasha in any organism, and novel alleles of dicer-1. Our screening recovered other suppressor mutations that do not map to known pathway components, as well as enhancer mutations that are dependent on the $\mathrm{w}$-miR trigger. We anticipate that the cloning and characterization of these mutations may provide additional insights into the miRNA biogenesis machinery or the mechanism of miRNA-mediated silencing.

\section{Hypomorphic alleles reveal a synaptic transmission defect caused by mild reduction of miRNA pathway activity}

miRNAs in whole organisms have to date mostly been studied for their roles in development. This is at least in part due to the early developmental defects that potentially mask later functional defects. Yet, miRNAs have long been viewed as a potentially key component of neural function and fine-tuning due to their regulatory potential. One tantalizing property of miRNAs is their ability to regulate gene expression locally. In neurons, where a synapse may be a great distance from the nucleus, this could provide a means for rapid post-transcriptional regulation of targets. How this may be regulated in a signal-dependent manner is a topic of ongoing study (Ashraf et al. 2006; Krol et al. 2010). In this study, we present novel hypomorphic mutants that mildly affect miRNA levels and cause synapse function defects without affecting development.

The requirement of neurons for precise miRNA activity is emphasized by the specific synaptic transmission defects in our hypomorphic miRNA pathway mutants. In weak alleles of either pasha or drosha, we observed only a mild reduction in miRNA biogenesis. While these animals quickly succumb just before or after adult eclosion, they exhibit grossly normal development of all external structures. Using whole eye clone analysis, we documented normal specification and projection of mutant photoreceptors, but substantial synaptic transmission defects that were very similar in drosha, pasha, and dicer-1 mutants. The lack of deterioration of this phenotype with age both argues for a specific synaptic transmission defect and also that the reduction in miRNA levels in these photoreceptor neurons does not affect their viability or general health.

The commonality of these phenotypes among the different mutants indicates underlying defective biogenesis of one or more canonical miRNAs, as opposed to mirtrons or other noncanonical species. It is conceivable that the synaptic transmission defect is caused by the cumulative effect of mildly reducing all photoreceptor miRNAs. However, the specificity of this phenotype and its critical dependence on optimal miRNA pathway function may imply that there is some aspect of synaptic transmission machinery that is especially sensitive to a more limited set of miRNAs. As the number of mutant strains for Drosophila miRNA loci steadily increases, it will be productive to screen them using ERGs on mutant eyes. An alternative approach may be to test miRNA sponges (Loya et al. 2009) expressed presynaptically, perhaps in a candidate screen of head-expressed miRNAs (Ruby et al. 2007b).

Since loss of single alleles is typically well tolerated at the organismal level, dose-sensitive loci are of particular relevance to human disease. DGCR8 is one of about 20 genes within the 22q11.2 locus deleted in patients with diGeorge syndrome, for which heterozygosity results in cognitive and behavioral impairments in humans. In a mouse model of diGeorge syndrome bearing the 22q11.2 microdeletion, heterozygosity of $d g c r 8$ contributes to a reduction in brain miRNAs (Stark et al. 2008). More recently, specific heterozygosity of $d g c r 8$ was shown to cause subtle but detectable defects in neural developmental and physiology, providing more direct evidence of $d g c r 8$ haploinsufficiency (Fenelon et al. 2011). In the Drosophila system, cells heterozygous for pasha[KO] have less Pasha protein than homozygous wild-type cells (Fig. $4 \mathrm{H}$ ). Accordingly, the levels of the GFP-ban sensor indicated that it was repressed more strongly in homozygous wild-type cells than in neighboring pasha[KO] heterozygous cells (Fig. 2I). Therefore, despite the operation of feedback mechanisms that regulate Microprocessor levels, pasha exhibits functional haploinsufficiency. Altogether, our studies reaffirm that subtle alterations in miRNA biogenesis can lead to detectable organismal phenotypes, helping to explain the lengths to which animal evolution has gone to maintain Microprocessor homeostasis. Reciprocally, our studies define Drosophila as a suitable system for future exploration of the unique sensitivity of neuronal function to miRNA activity.

\section{MATERIALS AND METHODS}

\section{Molecular biology and biochemistry}

\section{Generation of $w-m i R$}

pGUS-DsRed was generated by cloning the DsRed.T4 CDS from Red-H-Pelican (Barolo et al. 2004) as an NcoI(blunt)/NotI fragment into pGUS (Brodsky et al. 2000) cut with EcoRI(blunt)/NotI. We used the strategy of Hay and colleagues to reprogram the mir-6-1 backbone (Chen et al. 2007) to produce an miR targeted against the white 3' UTR. The partially complementary primers mir6.1 wmiRNA1 For: GGCAGCTTACTTAAACTTAATCACAGCCTTT AATGTTTACCATCGTCGGCACTGTCTATAAGTTAATATACCA TATC and mir6.1 wmiRNA1 Rev: AATAATGATGTTAGGCACT TTAGGTACTTACCATCGTCAATACTGTTTATAGATATGGTAT ATTAACTTATAGA were converted into a dsDNA template by PCR and used as template for a second round of PCR using primers mir6.1 5' NotI: gatcgcggccgcTTTAAAGTCCACAACTC ATCAAGGAAAATGAAAGTCAAAGTTGGCAGCTTACTTAAAC 
TTA and mir6.1 3' XbaI: gatctctagaAAAACGGCATGGTTATTCG TGTGCCAAAAAAAAAAAAAATTAAATAATGATGTTAGGCAC. This product was digested with NotI and XbaI and cloned into pGUS-DsRed. Transgenic animals were generated by standard $P$-element-mediated transformation (Bestgene). Lines with consistent pale-orange eye color on chromosomes II and III were recombined with eyFLP transgenes on these respective chromosomes. The presence of the eyFLP transgene was confirmed by PCR to the flp coding region.

\section{Drosha rescue construct}

The drosha genomic locus from the isogenized FRT42 strain we used for mutagenesis was amplified in two parts using Drosha $\mathrm{F}$ FseI: gatcggecggccAACTGATCCGCTTCCTGGCG and Drosha mid R: TAATGCCGGTGCGATAGAAGC for the $5^{\prime}$ half and Drosha mid F: GATGGCCAACATGTCGAAGCC and Drosha R NotI: gatcgcggccgcCAACGTCTCCTGAGCTCGCC for the 3' half. The overlapping region between these PCR products contains a unique Pcil restriction site. The $5^{\prime}$ half was digested with FseI/PciI and the $3^{\prime}$ half with PciI/NotI. These fragments were cloned into pBDP (Pfeiffer et al. 2008) cut with FseI/NotI. Transgenic animals were made by targeted transgenesis into the attP2 site on chromosome 3L.

\section{Pasha rescue transgene lacking $5^{\prime}$-UTR hairpins}

We cloned our previously described pasha genomic rescue construct (Martin et al. 2009) into pBDP, and the sequences comprising the $5^{\prime}$-UTR hairpins were replaced with unstructured sequences from GFP. For a detailed description of this construction, see Supplemental Figure 1.

\section{white $3^{\prime}$-UTR sensors}

The annotated white $3^{\prime}$ UTR and $\sim 150$ bases of downstream sequence was amplified with w $3^{\prime}$ UTR Not For: gatcgcggccgcCCG ACATATATCCGAAATAAC and w 3' UTR Xho Rev: gatcctc gagCTATAGGTCATATCTTGTTTTTA. The PCR product was digested with NotI and XhoI and cloned into both tub-GFP (Stark et al. 2003) and modified psiCHECK2 (Okamura et al. 2007). Luciferase sensor assays in S2 cells were performed as previously described (Okamura et al. 2007).

\section{Sequencing of mutant alleles}

Following identification of mutant alleles by complementation, alleles of interest were placed in trans with pasha[KO] (pasha alleles) or $D f(2 R)$ exel6055 (drosha alleles). Larvae hemizygous for the locus of interest were selected, and DNA was extracted and amplified by PCR using the same oligos used to generate genomic rescue constructs. The molecular lesions associated with each allele were determined by standard sequencing and comparison with the sequence of the nonmutagenized starting strain.

\section{Analysis of miRNA/mirtron processing}

qRT-PCR analyses were performed using previously described oligo sequences and protocols (Martin et al. 2009). For Northern analysis, we used TRIzol to isolate total RNA from wild-type larvae (Canton S) or larvae trans-heterozygous for the indicated mutant allele and
pasha[KO] (for pasha alleles) or Df(2R)exel6055 (for drosha alleles). Small RNA Northern blots were performed using polyacrylamide gels and LNA probes (Exiqon) as described (Okamura et al. 2007).

\section{Drosophila genetic screen}

We mutagenized flies by collecting about 50-70 males and starved them by placing them in a dry empty vial with Whatman paper for $\sim 8$ h. Flies were then fed overnight with a solution of 25 mM EMS in $20 \%$ sucrose injected onto the Whatman paper. The males were then given $8 \mathrm{~h}$ to recover on normal food before being mated with females in a freshly yeasted bottle. Typically, five vials of males were mutagenized in each round, and mated females were allowed to lay on three consecutive sets of bottles for $2 \mathrm{~d}$ each. The adult flies were then discarded.

The screen for chromosome $3 \mathrm{R}$ was performed as follows. Virgin females of the genotype w; GMR-w-miR, eyFLP; iso FRT82B were crossed with mutagenized males of the genotype w; Sco/CyO; isoFRT82B. $\mathrm{F}_{1}$ progeny with eye color mosaicism were crossed again with $w$; GMR-w-miR, eyFLP; isoFRT82B to check for germline transmission of the mutation. Progeny displaying mosaicism were crossed to $w$; Sco/CyO; MKRS/TM6B. As the mutagenized chromosome is superficially impossible to distinguish from the nonmutagenized chromosome, individual males (about 10) were then crossed to $w$; Sco/CyO; MKRS/TM6B, and stocks were generated that were $w$; Sco/CyO; FRT82B, mutant?/TM6B. Half of these stocks are expected to have the mutagenized FRT82B chromosome. One stock per original mutant that could reproduce the original phenotype when crossed to w; GMR-w-miR, eyFLP; iso FRT82B was kept. The screen on chromosome $2 \mathrm{R}$ was carried out with the same strategy as described for 3R, with the exception that an isogenized FRT42D chromosome and a GMR-w-miR, eyFLP chromosome III were used instead. Images of eye clones in adult animals presented are of the genotype w; GMR-w-miR, eyFLP/Sco or CyO; FRT82 [X]/ FRT82, where $[\mathrm{X}]$ denotes the appropriate pasha or $d c r$-1 allele or w; FRT42 [Y]/FRT42; GMR w-miR, eyFLP/MKRS or TM6B, where [Y] denotes the appropriate drosha allele.

\section{Clonal analysis and immunostaining}

We analyzed the functional properties of mutants isolated in this screen, as well as FRT82B pasha[KO] (Martin et al. 2009) and FRT82B dcr-1[Q1147X] (Lee et al. 2004), by introducing them into backgrounds carrying $h s-F L P$ and the miRNA sensor transgenes tub-GFP-bantam (Brennecke et al. 2003) or tub-GFP-dLMO 3' UTR (Bejarano et al. 2010). Chromosome 3R clones were generated in the genotype hs-FLP; GFP-ban/+; FRT82B [X]/ FRT82B, arm-lacZ (Fig. 2) or hs-FLP; FRT82B [X]/FRT82B, arm-lac $Z$ (Fig. 5), where $[\mathrm{X}]$ denotes the relevant mutant allele. Chromosome $2 \mathrm{R}$ clones were generated in the genotype $h s-F L P$; FRT42D [Y]/FRT42D, arm-lacZ; GFP-dLMO/+ (Fig. 2) or hsFLP; FRT42D [Y]/FRT42D, arm-lacZ (Fig. 5), where [Y] denotes the appropriate mutant allele. For Figure 5G, the genotype analyzed was hs-FLP; FRT42D, drosha[21K11]/FRT42D, arm-lacZ; attP2>pBDP pasha[ $\triangle \mathrm{HP}]$ rescue, pasha[KO].

Immunostaining was performed as previously described (Lai and Rubin 2001). Antibodies used were mouse anti- $\beta$-galactosidase (1/50) and rat anti-Elav (1/50) from the Developmental Studies Hybridoma Bank, Chicken anti-GFP (1/1000, Abcam), 
rabbit anti-Mei-P26 (1/1000) (Liu et al. 2009), rabbit anti-Pasha (1/1000), and rabbit anti-Drosha (1/1000) (Denli et al. 2004). We used appropriate secondary antibodies conjugated to Alexa 488, 568, and 647 (Molecular Probes).

\section{Electrophysiology}

Electroretinograms (ERGs) were performed as described in FabianFine et al. (2003) with the following modifications: Flies were fixed using Elmer's nontoxic Glue-All. We used $2 \mathrm{M} \mathrm{NaCl}$ in the recording and reference electrodes. Recordings were performed using a Warner IE-210 amplifier and Clampex 10.1 software by Axon Instruments. A post-recording filter was also provided by the Clampex software. Light stimulus was provided in 1-sec pulses by a computer-controlled white LED system (Schott MC1500).

The following genotypes were used:

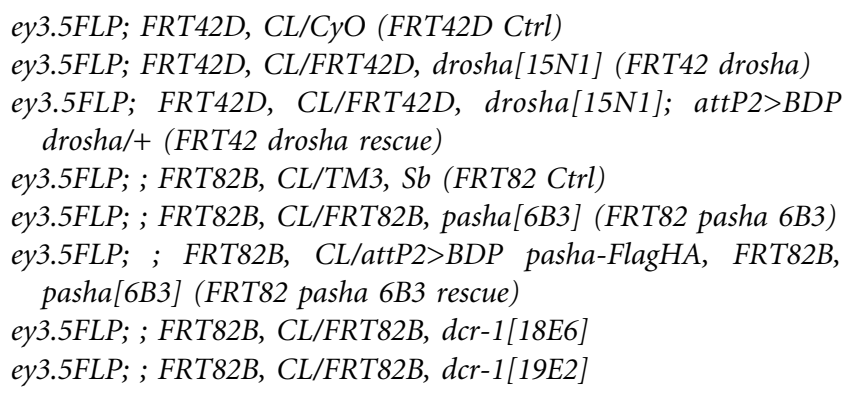

\section{SUPPLEMENTAL MATERIAL}

Supplemental material is available for this article.

\section{ACKNOWLEDGMENTS}

We are grateful to Drs. Richard Carthew, Greg Hannon, Paul Lasko, and Stephen Cohen; the Bloomington Drosophila Stock Center; and the Developmental Studies Hybridoma Bank for Drosophila stocks and antibodies that were critical for this study. Work in P.R.H.'s group was supported by the Welch Foundation (I-1657), the Cancer Prevention Research Institute of Texas (RP100516), and the NIH (R01EY018884). Work in E.C.L.'s group was supported by the Burroughs Wellcome Fund, the Alfred Bressler Scholars Fund, the Starr Cancer Consortium (I3A139), and the NIH (R01-GM083300).

Authors' contributions: P.S., P.R.H., and E.C.L. conceived and designed the experiments. P.S., F.B., D.W., D.L.G., J.Y., R.M., D.B.B., and N.R. performed the experiments. P.S., D.W., P.R.H., and E.C.L. analyzed the data. P.S., P.R.H., and E.C.L. wrote the paper.

Received August 10, 2011; accepted August 15, 2011.

\section{REFERENCES}

Ashraf SI, McLoon AL, Sclarsic SM, Kunes S. 2006. Synaptic protein synthesis associated with memory is regulated by the RISC pathway in Drosophila. Cell 124: 191-205.

Babiarz JE, Ruby JG, Wang Y, Bartel DP, Blelloch R. 2008. Mouse ES cells express endogenous shRNAs, siRNAs, and other Microprocessor-independent, Dicer-dependent small RNAs. Genes Dev 22: 2773-2785.
Barolo S, Castro B, Posakony JW. 2004. New Drosophila transgenic reporters: insulated P-element vectors expressing fast-maturing RFP. BioTechniques 36: 436-442.

Bartel DP. 2009. MicroRNAs: Target recognition and regulatory functions. Cell 136: 215-233.

Behm-Ansmant I, Rehwinkel J, Doerks T, Stark A, Bork P, Izaurralde E. 2006. mRNA degradation by miRNAs and GW182 requires both CCR4:NOT deadenylase and DCP1:DCP2 decapping complexes. Genes Dev 20: 1885-1898.

Bejarano F, Smibert P, Lai EC. 2010. miR-9a prevents apoptosis during wing development by repressing Drosophila LIM-only. Dev Biol 338: 63-73.

Bennasser Y, Chable-Bessia C, Triboulet R, Gibbings D, Gwizdek C, Dargemont C, Kremer EJ, Voinnet O, Benkirane M. 2011. Competition for XPO5 binding between Dicer mRNA, premiRNA and viral RNA regulates human Dicer levels. Nat Struct Mol Biol 18: 323-327.

Berdnik D, Fan AP, Potter CJ, Luo L. 2008. MicroRNA processing pathway regulates olfactory neuron morphogenesis. Curr Biol 18: 1754-1759.

Bohnsack MT, Czaplinski K, Gorlich D. 2004. Exportin 5 is a RanGTP-dependent dsRNA-binding protein that mediates nuclear export of pre-miRNAs. RNA 10: 185-191.

Brennecke J, Hipfner DR, Stark A, Russell RB, Cohen SM. 2003. bantam encodes a developmentally regulated microRNA that controls cell proliferation and regulates the proapoptotic gene hid in Drosophila. Cell 113: 25-36.

Brodsky MH, Nordstrom W, Tsang G, Kwan E, Rubin GM, Abrams JM. 2000. Drosophila p53 binds a damage response element at the reaper locus. Cell 101: 103-113.

Cheloufi S, Dos Santos CO, Chong MM, Hannon GJ. 2010. A dicerindependent miRNA biogenesis pathway that requires Ago catalysis. Nature 465: 584-589.

Chen $\mathrm{CH}$, Huang H, Ward CM, Su JT, Schaeffer LV, Guo M, Hay BA. 2007. A synthetic maternal-effect selfish genetic element drives population replacement in Drosophila. Science 316: 597600.

Chong MM, Rasmussen JP, Rudensky AY, Littman DR. 2008. The RNAseIII enzyme Drosha is critical in T cells for preventing lethal inflammatory disease. J Exp Med 205: 2005-2017.

Chotard C, Leung W, Salecker I. 2005. glial cells missing and $\mathrm{gcm} 2$ cell autonomously regulate both glial and neuronal development in the visual system of Drosophila. Neuron 48: 237-251.

Cifuentes D, Xue H, Taylor DW, Patnode H, Mishima Y, Cheloufi S, Ma E, Mane S, Hannon GJ, Lawson N, et al. 2010. A novel miRNA processing pathway independent of Dicer requires Argonaute2 catalytic activity. Science 328: 1694-1698.

Czech B, Zhou R, Erlich Y, Brennecke J, Binari R, Villalta C, Gordon A, Perrimon N, Hannon GJ. 2009. Hierarchical rules for Argonaute loading in Drosophila. Mol Cell 36: 445-456.

Denli A, Tops B, Plasterk R, Ketting R, Hannon G. 2004. Processing of primary microRNAs by the Microprocessor complex. Nature 432: 231-235.

Eulalio A, Rehwinkel J, Stricker M, Huntzinger E, Yang SF, Doerks T, Dorner S, Bork P, Boutros M, Izaurralde E. 2007. Target-specific requirements for enhancers of decapping in miRNA-mediated gene silencing. Genes Dev 21: 2558-2570.

Eulalio A, Huntzinger E, Izaurralde E. 2008. GW182 interaction with Argonaute is essential for miRNA-mediated translational repression and mRNA decay. Nat Struct Mol Biol 15: 346-353.

Fabian-Fine R, Verstreken P, Hiesinger PR, Horne JA, Kostyleva R, Zhou Y, Bellen HJ, Meinertzhagen IA. 2003. Endophilin promotes a late step in endocytosis at glial invaginations in Drosophila photoreceptor terminals. J Neurosci 23: 10732-10744.

Fénelon K, Mukai J, Xu B, Hsu PK, Drew LJ, Karayiorgou M, Fischbach GD, Macdermott AB, Gogos JA. 2011. Deficiency of $D g c r 8$, a gene disrupted by the 22q11.2 microdeletion, results in altered short-term plasticity in the prefrontal cortex. Proc Natl Acad Sci 108: 4447-4452. 
Flynt AS, Lai EC. 2008. Biological principles of microRNA-mediated regulation: shared themes amid diversity. Nat Rev Genet 9: 831842.

Flynt AS, Chung WJ, Greimann JC, Lima CD, Lai EC. 2010. microRNA biogenesis via splicing and exosome-mediated trimming in Drosophila. Mol Cell 38: 900-907.

Forman JJ, Legesse-Miller A, Coller HA. 2008. A search for conserved sequences in coding regions reveals that the let-7 microRNA targets Dicer within its coding sequence. Proc Natl Acad Sci 105: 14879-14884.

Förstemann K, Tomari Y, Du T, Vagin V, Denli A, Bratu D, Klattenhoff C, Theurkauf W, Zamore P. 2005. Normal microRNA maturation and germ-line stem cell maintenance requires Loquacious, a double-stranded RNA-binding domain protein. PLoS Biol 3: e236. doi: 10.1371/journal.pbio.0030236.

Förstemann K, Horwich MD, Wee L, Tomari Y, Zamore PD. 2007. Drosophila microRNAs are sorted into functionally distinct argonaute complexes after production by Dicer-1. Cell 130: 287-297.

Fukuda T, Yamagata K, Fujiyama S, Matsumoto T, Koshida I, Yoshimura K, Mihara M, Naitou M, Endoh H, Nakamura T, et al. 2007. DEAD-box RNA helicase subunits of the Drosha complex are required for processing of rRNA and a subset of microRNAs. Nat Cell Biol 9: 604-611.

Ghildiyal M, Xu J, Seitz H, Weng Z, Zamore PD. 2010. Sorting of Drosophila small silencing RNAs partitions microRNA* strands into the RNA interference pathway. RNA 16: 43-56.

Gregory RI, Yan KP, Amuthan G, Chendrimada T, Doratotaj B, Cooch N, Shiekhattar R. 2004. The Microprocessor complex mediates the genesis of microRNAs. Nature 432: 235-240.

Han J, Lee Y, Yeom KH, Kim YK, Jin H, Kim VN. 2004. The DroshaDGCR8 complex in primary microRNA processing. Genes Dev 18: 3016-3027.

Han J, Lee Y, Yeom KH, Nam JW, Heo I, Rhee JK, Sohn SY, Cho Y, Zhang BT, Kim VN. 2006. Molecular basis for the recognition of primary microRNAs by the Drosha-DGCR8 complex. Cell 125: 887-901.

Han J, Pedersen JS, Kwon SC, Belair CD, Kim YK, Yeom KH, Yang WY, Haussler D, Blelloch R, Kim VN. 2009. Posttranscriptional crossregulation between Drosha and DGCR8. Cell 136: 75-84.

Hatfield SD, Shcherbata HR, Fischer KA, Nakahara K, Carthew RW, Ruohola-Baker H. 2005. Stem cell division is regulated by the microRNA pathway. Nature 435: 974-978.

Herranz H, Hong X, Perez L, Ferreira A, Olivieri D, Cohen SM, Milan M. 2010. The miRNA machinery targets Mei-P26 and regulates Myc protein levels in the Drosophila wing. EMBO J 29: 1688-1698.

Jin Z, Xie T. 2007. Dcr-1 maintains Drosophila ovarian stem cells. Curr Biol 17: 539-544.

Kadener S, Rodriguez J, Abruzzi KC, Khodor YL, Sugino K, Marr MT II, Nelson S, Rosbash M. 2009. Genome-wide identification of targets of the drosha-pasha/DGCR8 complex. RNA 15: 537-545.

Kim K, Lee YS, Carthew RW. 2007. Conversion of pre-RISC to holoRISC by Ago2 during assembly of RNAi complexes. RNA 13: 22-29.

Kim VN, Han J, Siomi MC. 2009. Biogenesis of small RNAs in animals. Nat Rev Mol Cell Biol 10: 126-139.

Krol J, Busskamp V, Markiewicz I, Stadler MB, Ribi S, Richter J, Duebel J, Bicker S, Fehling HJ, Schubeler D, et al. 2010. Characterizing light-regulated retinal microRNAs reveals rapid turnover as a common property of neuronal microRNAs. Cell 141: $618-631$

Lai EC. 2002. microRNAs are complementary to $3^{\prime}$ UTR sequence motifs that mediate negative post-transcriptional regulation. Nat Genet 30: 363-364.

Lai EC, Posakony JW. 1997. The Bearded box, a novel 3' UTR sequence motif, mediates negative post-transcriptional regulation of Bearded and Enhancer of split Complex gene expression. Development 124: 4847-4856.

Lai EC, Rubin GM. 2001. neuralized functions cell-autonomously to regulate a subset of Notch-dependent processes during adult Drosophila development. Dev Biol 231: 217-233.
Lai EC, Burks C, Posakony JW. 1998. The K box, a conserved 3' UTR sequence motif, negatively regulates accumulation of Enhancer of split complex transcripts. Development 125: 4077-4088.

Landthaler M, Yalcin A, Tuschl T. 2004. The human DiGeorge syndrome critical region gene 8 and its D. melanogaster homolog are required for miRNA biogenesis. Curr Biol 14: 2162-2167.

Lee Y, Ahn C, Han J, Choi H, Kim J, Yim J, Lee J, Provost P, Radmark O, Kim S, et al. 2003. The nuclear RNase III Drosha initiates microRNA processing. Nature 425: 415-419.

Lee YS, Nakahara K, Pham JW, Kim K, He Z, Sontheimer EJ, Carthew RW. 2004. Distinct roles for Drosophila Dicer-1 and Dicer-2 in the siRNA/miRNA silencing pathways. Cell 117: 69-81.

Lee YS, Pressman S, Andress AP, Kim K, White JL, Cassidy JJ, Li X, Lubell K, Lim DH, Cho IS, et al. 2009. Silencing by small RNAs is linked to endosomal trafficking. Nat Cell Biol 11: 1150-1156.

Lim H, Kim J, Kim S, Carthew RW, Lee YS. 2008. Functional analysis of dicer-2 missense mutations in the siRNA pathway of Drosophila. Biochem Biophys Res Commun 371: 525-530.

Liu J, Rivas FV, Wohlschlegel J, Yates JR III, Parker R, Hannon GJ. 2005. A role for the P-body component GW182 in microRNA function. Nat Cell Biol 7: 1161-1166.

Liu N, Han H, Lasko P. 2009. Vasa promotes Drosophila germline stem cell differentiation by activating mei-P26 translation by directly interacting with a (U)-rich motif in its $3^{\prime}$ UTR. Genes Dev 23: 2742-2752.

Loya CM, Lu CS, Van Vactor D, Fulga TA. 2009. Transgenic microRNA inhibition with spatiotemporal specificity in intact organisms. Nat Methods 6: 897-903.

Lund E, Guttinger S, Calado A, Dahlberg J, Kutay U. 2004. Nuclear export of microRNA precursors. Science 303: 95-98.

Marques JT, Kim K, Wu PH, Alleyne TM, Jafari N, Carthew RW. 2010. Loqs and R2D2 act sequentially in the siRNA pathway in Drosophila. Nat Struct Mol Biol 17: 24-30.

Martello G, Rosato A, Ferrari F, Manfrin A, Cordenonsi M, Dupont S, Enzo E, Guzzardo V, Rondina M, Spruce T, et al. 2010. A microRNA targeting dicer for metastasis control. Cell 141: 11951207.

Martin R, Smibert P, Yalcin A, Tyler DM, Schaefer U, Tuschl T, Lai EC. 2009. A Drosophila pasha mutant distinguishes the canonical miRNA and mirtron pathways. Mol Cell Biol 29: 861-870.

Mehta SQ, Hiesinger PR, Beronja S, Zhai RG, Schulze KL, Verstreken P, Cao Y, Zhou Y, Tepass U, Crair MC, et al. 2005. Mutations in Drosophila sec15 reveal a function in neuronal targeting for a subset of exocyst components. Neuron 46: 219-232.

Okamura K, Hagen JW, Duan H, Tyler DM, Lai EC. 2007. The mirtron pathway generates microRNA-class regulatory RNAs in Drosophila. Cell 130: 89-100.

Okamura K, Liu N, Lai EC. 2009. Distinct mechanisms for microRNA strand selection by Drosophila Argonautes. Mol Cell 36: 431-444.

Park JK, Liu X, Strauss TJ, McKearin DM, Liu Q. 2007. The miRNA pathway intrinsically controls self-renewal of Drosophila germline stem cells. Curr Biol 17: 533-538.

Parry DH, Xu J, Ruvkun G. 2007. A whole-genome RNAi screen for C. elegans miRNA pathway genes. Curr Biol 17: 2013-2022.

Pfeiffer BD, Jenett A, Hammonds AS, Ngo TT, Misra S, Murphy C, Scully A, Carlson JW, Wan KH, Laverty TR, et al. 2008. Tools for neuroanatomy and neurogenetics in Drosophila. Proc Natl Acad Sci 105: 9715-9720.

Rajagopalan R, Vaucheret H, Trejo J, Bartel DP. 2006. A diverse and evolutionarily fluid set of microRNAs in Arabidopsis thaliana. Genes Dev 20: 3407-3425.

Rehwinkel J, Behm-Ansmant I, Gatfield D, Izaurralde E. 2005. A crucial role for GW182 and the DCP1:DCP2 decapping complex in miRNA-mediated gene silencing. RNA 11: 1640-1647.

Ruby JG, Jan CH, Bartel DP. 2007a. Intronic microRNA precursors that bypass Drosha processing. Nature 448: 83-86.

Ruby JG, Stark A, Johnston WK, Kellis M, Bartel DP, Lai EC. 2007b. Evolution, biogenesis, expression, and target predictions of a sub- 
stantially expanded set of Drosophila microRNAs. Genome Res 17: $1850-1864$.

Ryder E, Ashburner M, Bautista-Llacer R, Drummond J, Webster J, Johnson G, Morley T, Chan YS, Blows F, Coulson D, et al. 2007. The DrosDel deletion collection: A Drosophila genomewide chromosomal deficiency resource. Genetics 177: 615-629.

Saito K, Ishizuka A, Siomi H, Siomi MC. 2005. Processing of premicroRNAs by the Dicer-1-Loquacious complex in Drosophila cells. PLoS Biol 3: e235. doi: 10.1371/journal.pbio.0030235.

Stark A, Brennecke J, Russell RB, Cohen SM. 2003. Identification of Drosophila microRNA targets. PLoS Biol 1: e60. doi: 10.1371/ journal.pbio.0000060.

Stark KL, Xu B, Bagchi A, Lai WS, Liu H, Hsu R, Wan X, Pavlidis P, Mills AA, Karayiorgou M, et al. 2008. Altered brain microRNA biogenesis contributes to phenotypic deficits in a 22q11-deletion mouse model. Nat Genet 40: 751-760.

Stowers RS, Schwarz TL. 1999. A genetic method for generating Drosophila eyes composed exclusively of mitotic clones of a single genotype. Genetics 152: 1631-1639.

Tomari Y, Matranga C, Haley B, Martinez N, Zamore PD. 2004. A protein sensor for siRNA asymmetry. Science 306: 1377-1380.

Tomari Y, Du T, Zamore PD. 2007. Sorting of Drosophila small silencing RNAs. Cell 130: 299-308.

Triboulet R, Chang HM, Lapierre RJ, Gregory RI. 2009. Posttranscriptional control of DGCR8 expression by the Microprocessor. RNA 15: 1005-1011.

Vaucheret H, Vazquez F, Crété P, Bartel DP. 2004. The action of ARGONAUTE1 in the miRNA pathway and its regulation by the miRNA pathway are crucial for plant development. Genes Dev 18: 1187-1197.
Vaucheret H, Mallory AC, Bartel DP. 2006. AGO1 homeostasis entails coexpression of MIR168 and AGO1 and preferential stabilization of miR168 by AGO1. Mol Cell 22: 129-136.

Williamson WR, Wang D, Haberman AS, Hiesinger PR. 2010. A dual function of V0-ATPase al provides an endolysosomal degradation mechanism in Drosophila melanogaster photoreceptors. J Cell Biol 189: 885-899.

Wu H, Xu H, Miraglia LJ, Crooke ST. 2000. Human RNase III is a $160-\mathrm{kDa}$ protein involved in preribosomal RNA processing. J Biol Chem 275: 36957-36965.

Xie Z, Kasschau KD, Carrington JC. 2003. Negative feedback regulation of Dicer-like1 in Arabidopsis by microRNA-guided mRNA degradation. Curr Biol 13: 784-789.

Yang JS, Lai EC. 2011. Alternative miRNA biogenesis pathways and the interpretation of core miRNA pathway mutants. Mol Cell 43: 892-903.

Yang JS, Maurin T, Robine N, Rasmussen KD, Jeffrey KL, Chandwani R, Papapetrou EP, Sadelain M, O'Carroll D, Lai EC. 2010. Conserved vertebrate mir-451 provides a platform for Dicerindependent, Ago2-mediated microRNA biogenesis. Proc Natl Acad Sci 107: 15163-15168.

Yi R, Qin Y, Macara IG, Cullen BR. 2003. Exportin-5 mediates the nuclear export of pre-microRNAs and short hairpin RNAs. Genes Dev 17: 3011-3016.

Zdanowicz A, Thermann R, Kowalska J, Jemielity J, Duncan K, Preiss T, Darzynkiewicz E, Hentze MW. 2009. Drosophila miR2 primarily targets the $\mathrm{m}^{7} \mathrm{GpppN}$ cap structure for translational repression. Mol Cell 35: 881-888.

Zhou R, Hotta I, Denli AM, Hong P, Perrimon N, Hannon GJ. 2008. Comparative analysis of Argonaute-dependent small RNA pathways in Drosophila. Mol Cell 32: 592-599. 

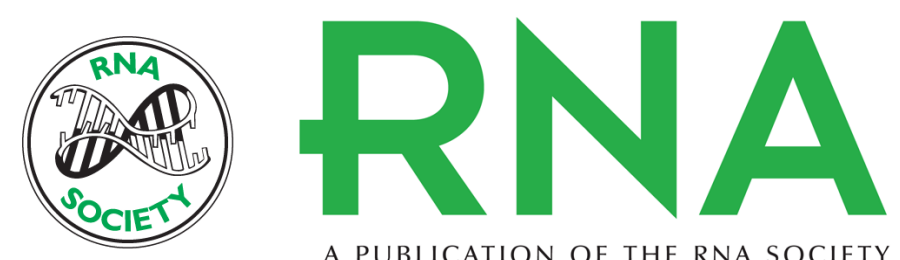

A PUBLICATION OF THE RNA SOCIETY

\section{A Drosophila genetic screen yields allelic series of core microRNA biogenesis factors and reveals post-developmental roles for microRNAs}

Peter Smibert, Fernando Bejarano, Dong Wang, et al.

RNA 2011 17: 1997-2010 originally published online September 23, 2011

Access the most recent version at doi:10.1261/rna.2983511

Supplemental http://rnajournal.cshlp.org/content/suppl/2011/08/24/rna.2983511.DC1

Material

References This article cites 84 articles, 30 of which can be accessed free at:

http://rnajournal.cshlp.org/content/17/11/1997.full.html\#ref-list-1

License

Email Alerting Receive free email alerts when new articles cite this article - sign up in the box at the Service top right corner of the article or click here. 